\title{
Roberto Mario Amaral Lima Filho
}

O Board Brasileiro de Ortodontia e Ortopedia Facial é uma conquista para a especialidade, sendo o primeiro exame do tipo implementado no país. Em março último ocorreu o segundo exame que certificou mais 9 especialistas e consolidou o BBO como uma instituição confível e que age em prol da ortodontia nacional. Buscando oferecer alguns esclarecimentos sobre o exame, entrevistamos o Dr. Roberto Mario Amaral Lima Filho, Diretor Presidente do BBO. Além do Dr. Roberto, compõem a diretoria do Board, Dr. Carlos Jorge Vogel (Diretor Presidente Eleito), Dr. Estélio Zen (Diretor Secretário), Dr. Ana Maria Bolognese (Diretor Tesoureiro), Dr. José Nelson Mucha ( $1^{\circ}$ Diretor), Dr. Telma Martins de Araújo (2 ${ }^{\circ}$ Diretor), Dr. Ademir Brunetto ( $3^{\circ}$ Diretor) e Dr. Deocleciano da Silva Carvalho ( $4^{\circ}$ Diretor).

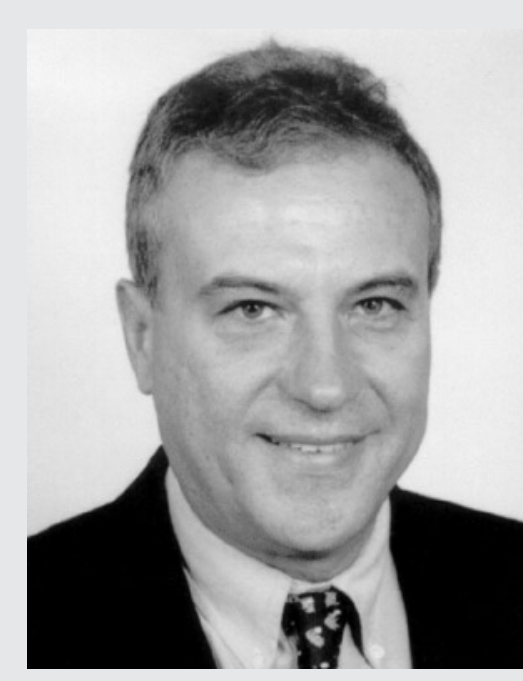

- Pós-graduado em Ortodontia pela Universidade de Illinois em Chicago, EUA

- Mestre em Ortodontia pela Universidade Federal do Rio de Janeiro (UFRJ).

- Diplomado pelo American Board of Orthodontics (ABO).

- Membro do Midwest Component of Edward H. Angle Society..
1) $O$ que impulsionou a criação do exame para especialistas em Ortodontia e Ortopedia Facial, o exame do Board Brasileiro de Ortodontia e Ortopedia Facial (BBO)?

Graças a uma iniciativa da Associação Brasileira de Ortodontia e Ortopedia Facial (ABOR), o Board Brasileiro de Ortodontia e Ortopedia Facial (BBO) foi criado devido à necessidade de estabelecer padrões de excelência clínica no exercício da especialidade Ortodontia e Ortopedia Facial. Vale destacar, que o Board de Ortodontia foi pioneiro na área da saúde em nosso país.

\section{2) Considerando que foram necessários} alguns anos para a implantação do BBO e que já foram realizados dois exames de certificação, quais os principais resultados obtidos pelo Board Brasileiro de Ortodontia e Ortopedia Facial?

O Board Brasileiro de Ortodontia e Ortopedia Facial (BBO) foi oficializado em setembro de 2002. Até o presente, foram feitos dois exames de certificação, realizados em São Paulo (2004) e São José do Rio Preto (2005), sendo diplomados especialistas provenientes de 11 estados brasileiros. Além disso, em abril de 2005 foi oficializada a criação do 
Colégio dos Diplomados do Board Brasileiro de Ortodontia e Ortopedia Facial (CDBBO).

\section{3) Quais são as etapas do exame?}

Os dois primeiros exames foram divididos em duas partes: a) avaliação de 2 casos apresentados pelo $\mathrm{BBO}$ e b) avaliação de 10 casos tratados pelos candidatos. A partir de 2006, o exame será dividido em 3 fases: Inscrição (Fase I), Diagnóstico e Planejamento (Fase II) e Exame Clínico (Fase III).

4) Houve alguma mudança importante no exame de certificação do Board Brasileiro de Ortodontia e Ortopedia Facial (BBO)?

A partir do próximo exame, os especialistas em Ortodontia recém-formados poderão efetuar suas inscrições (Fase I) e o exame de diagnóstico e planejamento (Fase II).

\section{5) Que tipos de casos devem ser apresen- tados?}

O candidato deverá apresentar 10 casos tratados em seu consultório particular, sendo que 6 deles devem se enquadrar nas categorias descritas abaixo.

- Má oclusão Classe II ou III de Angle, tratada sem extração e com controle de crescimento;

- Má oclusão Classe I de Angle, tratada com extrações de dentes permanentes, excluindo os terceiros molares;

- Má oclusão Classe II de Angle, tratada com extração de dentes permanentes, exceto os terceiros molares;

- Má oclusão com discrepância anteroposterior acentuada (Classe III de Angle com ANB igual ou maior que - $2^{\circ}$ ou Classe II de Angle com ANB igual ou maior que $5^{\circ}$ );

- Má oclusão com problema transverso, apresentando pelo menos um quadrante em cruzamento;

- Má oclusão com sobremordida acentuada;

- Escolha livre (4 casos);

6) Para a fase de apresentação dos casos tratados, quais os quesitos para a documenta- ção (fotográfica, modelos, cefalométrica...)? Ou seja, quais as orientações para quem quer candidatar-se ao BBO?

A documentação dos casos apresentados deve ser de qualidade e incluir modelos, radiografias (panorâmica ou periapicais e cefalométricas) e fotografias (faciais e intra-orais). A documentação pós-tratamento dos casos pode ser obtida até 1 ano após a remoção do aparelho. Em toda documentação os nomes dos candidatos devem estar rigorosamente encobertos com tarjas em preto ou branco, devendo constar somente o Código de Identificação do candidato (CI). Para possibilitar uma avaliação mais uniforme e equilibrada, é necessário que a documentação siga uma padronização. Os requisitos estabelecidos para o recorte dos modelos, para a avaliação cefalométrica (traçados cefalométricos, medidas angulares e lineares e superposições cefalométricas), e fotografias, devem ser seguidas de acordo com os padrões establececidos pelo BBO. Exames e dados complementares (tais como radiografias adicionais, medidas cefalométricas) podem ser apresentados, se o candidato entender que são necessários para melhor compreensão dos casos.

Os modelos apresentados devem copiar fielmente as arcadas dentárias e a região do vestíbulo, reproduzindo com precisão a má oclusão. Os modelos devem ser recortados em MIH. O ajuste ou escultura na porção anatômica (dentes e vestíbulo) dos modelos deve se limitar à eliminação de bolhas ou defeitos. A alteração da anatomia dos dentes é considerada falsificação da documentação, o que ocasionará automaticamente a reprovação desse caso. Aparelhos de contenção fixa podem estar presentes em modelos finais e pós-tratamento. Os modelos devem ser polidos de modo que os detalhes dos tecidos sejam preservados. As etiquetas para identificação devem ser padronizadas. As radiografias panorâmicas, periapicais e complementares devem ser de boa qualidade. Os filmes devem estar orientados corretamente, com os lados direito e esquerdo identificados claramente. 
Radiografias panorâmicas sem definição satisfatória naregiãodosincisivos(superioreseinferiores)devem ser complementadas com radiografias periapicais dessas áreas.

As radiografias de perfil devem ser devidamente padronizadas e as estruturas ósseas e o perfil tegumentar bem nítidos. Em casos de assimetria facial evidente, além de radiografias de perfil, deverão ser apresentadas radiografias cefalométricas póstero-anteriores, devidamente analisadas. O nome do candidato deve estar encoberto com tarjas em preto ou branco para preservar o sigilo durante o exame. O nome do paciente e a data devem permanecer visíveis.

Os traçados cefalométricos devem ser realizados pelo candidato, manualmente e com precisão, sobre um papel de acetato, com caneta ou lápis com até $0,5 \mathrm{~mm}$ de diâmetro, contendo apenas os detalhes anatômicos de interesse para as análises clínicas e sobreposições cefalométricas. Traçados gerados por computador não serão aceitos. Gabaritos para traçar o contorno dos dentes como, por exemplo "Tooth Tracing Template" 701-603 Unitek podem ser usados. Os pontos cefalométricos devem ser cuidadosamente identificados para garantir a confiabilidade nas linhas de referência obtidas. Para avaliação do padrão esquelético, dentário e do perfil facial, devem ser utilizadas as medidas da tabela 1, disposta no site www.bbo.org.br. O candidato poderá acrescentar outras medidas se julgar necessário.

A identificação dos traçados cefalométricos deverá seguir a orientação de identificação mencionada nas radiografias cefalométricas. As linhas e medidas registradas nos traçados das diferentes fases deverão ser na cor preta. $O$ candidato deve estar familiarizado com todos os aspectos das radiografias cefalométricas, traçados e medidas, incluindo seus respectivos significados. Os traçados devem ser separados das telerradiografias.

Serão necessárias, no mínimo, três sobreposições de traçados: craniofacial, maxilar e mandibular: a) Craniofacial (ou total)- registro entre as grandes asas do esfenóide com a melhor adaptação das estruturas ósseas do plano do esfenóide e lâmina crivosa do etmóide ou com registro no ponto Sela, utilizando a linha Sela-Násio para avaliar o crescimento geral e alterações do tratamento;

b) Maxilar - registro na curvatura palatina e maior aproximação das estruturas ósseas maxilares para avaliar a movimentação dos dentes superiores;

c) Mandibular - registro no contorno da cortical interna da sínfise com melhor sobreposição no limite inferior do corpo mandibular para avaliar movimento dentário na arcada inferior e crescimento da mandíbula.

As sobreposições devem ser colocadas em envelopes separados, sobre papel branco, sem serem afixadas.

$\mathrm{Na}$ documentação fotográfica, os pacientes devem ter, em cada fase, os seguintes registros:

a) uma fotografia frontal (obrigatória);

b) uma fotografia de perfil do lado direito (obrigatória);

c) sempre que possível, uma fotografia frontal em sorriso (opcional) .

As fotografias faciais de frente e perfil devem estar orientadas com o plano horizontal de Frankfort paralelo ao solo e tiradas com os lábios em repouso, retratando a real situação do relacionamento labial do paciente. As fotografias devem estar o mais próximo possível de $1 / 4$ do tamanho real. Essas fotografias devem ser impressas em papel de qualidade fotográfica em orientação paisagem. Elas devem estar o mais próximo possível de $1 / 4$ do tamanho real, do topo da cabeça à parte inferior do queixo. Pode-se determinar se uma fotografia está a $1 / 4$ do tamanho original, medindo-se a distância vertical do paciente da linha do cabelo até a borda inferior do queixo. Se, por exemplo, a distância for $20 \mathrm{~cm}$, a dimensão na fotografia deve ser $5 \mathrm{~cm}$ ou $1 / 4$ do tamanho real. 
É importante ressaltar, ainda, alguns aspectos na obtenção das fotografias faciais, tais como: o fundo deve ser neutro; a iluminação de boa qualidade para revelar contornos faciais sem sombras; as orelhas devem estar expostas, visando orientação facial; os olhos abertos e direcionados para frente; óculos e outros acessórios devem ser retirados.

Cada caso deve ser documentado com três registros: uma vista frontal, uma vista lateral direita e uma vista lateral esquerda, com os dentes em máxima intercuspidação. Essas fotografias devem ser orientadas pelo plano oclusal. Fotografias opcionais podem ser incluídas, como vistas oclusais das arcadas dentárias superior e inferior, devendo ser o mais próximo possível da proporção 1:1 com os dentes do paciente. Se imagens de espelho forem utilizadas, a impressão deve ser invertida e as imagens montadas como se estivéssemos olhando para o paciente.

É importante observar, ainda, alguns aspectos na obtenção das fotografias intra-orais como: den- tes limpos, livre de placa bacteriana, sangramento ou saliva; utilizar retratores de lábios; a iluminação deve mostrar os contornos anatômicos com mínima quantidade de sombra; padronização das cores; evitar interferências visuais (retratores de lábios, rótulos e dedos).

Se as imagens das fotografias faciais e intra-bucais forem geradas no computador, devem ter alta resolução de cor e nitidez, e revelar com precisão os tecidos moles e duros. Os candidatos devem ter em mente que toda a documentação apresenta valor legal inerente, não podendo ser alterada.

Para as má oclusões com desarmonias esqueléticas acentuadas, com indicação de tratamento ortodôntico associado à cirurgia ortognática, a documentação pré-operatória imediata será necessária.

Informações adicionais sobre documentos, inclusive com exemplos fotográficos encontram-se no manual do candidato que está disponível no site www.bbo.org.br. 